\title{
STUDY ON LEARNING THE BOCCE-SPECIFIC TECHNIQUE
}

\author{
Valeria BĂLAN ${ }^{*}$, Nadija STRAZDINA², Iveta DIRZININKA ${ }^{3}$, Ana Maria MUJEA ${ }^{1}$ \\ ${ }^{1}$ National University of Physical Education and Sport, Faculty of Physical Education and Sport, Bucharest, \\ Romania \\ ${ }^{2}$ Latvian Academy of Sports Education, Riga, Latvia \\ ${ }^{3}$ Viduskurzeme Primary School, Development Centre, Pelci, Latvia \\ *Corresponding author: valiswim@yahoo.com
}

DOI: https://doi.org/10.51267/icpesk2020bp01

\begin{abstract}
The truth that the physical exercises practiced either independently or systematically has beneficial effects on the whole body has long been demonstrated and supported by empirical or scientific studies. Subsequently, this assertion was also proved in the case of people with intellectual disabilities. For this category of population, the level of learning various motor skills is different from one individual to another. There are periods when the learning is very fast, the pace being close to that of valid individuals. However, these periods alternate with periods of stagnation or even regression. In the learning phase, successful attempts are rare and technically incorrect. Gradually, people with Down syndrome manage to learn the technique specific to a sport discipline and commonly use it according to their needs and the specific circumstances. In this context, the present study aimed to identify how athletes with Down syndrome have learned and enhanced the technique specific to the game of bocce, especially the technique of releasing the ball. For this, we tested 16 athletes with Down syndrome (10 children and 6 adults; 8 girls and 8 boys) who were members of the target group included in the Erasmus+ Sport 590526 project. The methods used to conduct the study were: documentation, experiment, statistics and graphical representation. The test applied to the research subjects, namely the divisioning bocce test, resulted in the recording of higher performances for 10 athletes, while the performances of the other athletes were not statistically significant.
\end{abstract}

Keywords: technique, learning, bocce, Down syndrome.

\section{Introduction}

The truth that practicing independent or systematic physical exercise has beneficial effects on the whole body has long been demonstrated and supported by empirical or scientific studies. Subsequently, this statement also proved to be true for people with intellectual disabilities.

Initially used in recovery and development programmes, the learning of work skills and abilities helps subjects with mental retardation to gain functional independence (Teodorescu et al., 2007). After consolidation, these skills can be flexibly used (Neagu \& Papp, 2012; Bota, 2016) and can be transferred and applied to new situations so that people feel safe and want to continue learning new skills.

Stimulating the desire of people with Down syndrome to gain motor skills is important because they are known to be less active (Sharav \& Bowman, 1992), and lack of movement leads to an obvious bio-psycho-social delay (Lauteslager, 2005; Teodorescu et al., 2007; Malak et al., 2013; Malak et al., 2015). Moreover, acquisitions do not progress automatically (Mureșan \& Coman, 2011), but motricity needs to be constantly stimulated from the outside during the instructive-educational process, mostly within and by the family. This stimulation should begin in childhood (Braneț, 2016) and continue throughout life (Kazakova, 2018). More attention should be paid to girls, who are less active than boys (Bota, 2016), so that their level of motor skills reaches the level of disability-specific landmarks but also the age-specific level. 
Motor acquisitions largely depend on each individual. There are periods when learning occurs very quickly (at a pace quite close to that of non-disabled people) (Mureșan \& Coman, 2011), but also periods of stagnation or obvious regression. This is supported by Lauteslager (2005), who believes that motor behaviour is formed across successive phases. Permanent external stimulation leads to gains on all levels until old age, but practice is the prerequisite for maintaining these acquisitions, and forgetting is limited (Lauteslager, 2005).

In the learning process, special emphasis should be placed on correctly performing the movement. The systematic practice of a wrong movement causes the incorrect consolidation of that skill. Subsequent attempts to correct it require a long period of time, countless repetitions and patience from both the subject with disabilities and the coordinating teacher. This period is longer in the case of people with mental retardation because their moderate intelligence quotient (IQ) makes learning difficult (Gilderthorp et al., 2017). Marcu et al. (2001) think that people with Down syndrome whose IQ is between 60 and 70 can learn the motor skills specific to any sports discipline. If the IQ is below 60, motor learning difficulties are greater. Under these circumstances, several sports disciplines have adapted and/ or modified their regulations, providing various facilities for people with mental retardation.

Basic and applied utilitarian motor skills should be primordial motor acquisitions because they are a key factor in determining the level of physical activity, physical fitness and body composition (Bota, 2016). Based on them, one can later learn the technique specific to certain sports disciplines.

In the phase of motor skill learning, successful attempts are rare and technically incorrect. Gradually, people with Down syndrome manage to learn the technique specific to a sports discipline, and then regularly use it according to needs and circumstances (Mureșan \& Coman, 2011). It is important for the external stimulation to arouse their curiosity and bring novelty elements that make them want to repeat and practice the acquired skills.

People with Down syndrome generally learn by imitation (Bota, 2016) because their cognitive phenotype is characterised by strengths in visual memory, visual-motor integration and visual imitation (Fidler, 2005). Therefore, their participation, communication and integration in different activities alongside other people with or without disabilities influence and foster learning. Even if integrated into an entity where they have the opportunity to exercise, people with Down syndrome still need help, given that learning is done in small steps and is based on acquired motor behaviour and experiences gained in previous phases (Lauteslager, 2005).

In order to break monotony during recovery programmes, the intervention plan specialised in adapted sports activities can be implemented (Teodorescu et al., 2007). These activities are beneficial for people with Down syndrome, giving them the opportunity to practice new, unique motor skills that help them acquire a higher degree of autonomy. At the same time, they simultaneously stimulate several areas of development (Malak et al., 2013; Davlet'yarova et al., 2015), which leads to motor but also emotional, cognitive and social improvements (Doban, 2008).

The choice of sports activities must take into account the severity of mental disability, the functional abilities and the age of people with Down syndrome, as well as environmental factors (Marques-Aleixo, et al., 2013), but especially what each person likes to do. 
Another aspect that must be considered refers to the fact that some subjects with Down syndrome have difficulty making the transition from one movement to another, while others cannot perform simple movements or cannot easily perform simple movements, but can perform very complex movements, with a high degree of technicality.

Depending on the difficulty of the technique to be learned, the time needed to consolidate and improve it is different from one subject to another. However, learning also depends on the other components of motor ability that are used by the skills to be learned, such as the level of motor skills (Dragnea et al., 2006).

The game of bocce falls into the category of sports disciplines where precision in movement is essential for achieving good performance.

The bocce technique includes simple motor skills that are easy to perform. They aim at handling the pallina and bocce balls according to the game regulations. All technical elements are subordinated to the goal: throwing the pallina so as to place it inside the statutory area and throwing/rolling the balls in optimal conditions so as they stop as close to the pallina as possible (Special Olympics, 2005).

According to Bocce Coaching Guide (Special Olympics, 2005, complemented by Bălan et al. (2019), the bocce technique includes:

a) the ball pick-up - is the technical element by which the player takes possession of the ball. The ball is recommended to be hold with both hands in order to better control it and be sure it does not drop from hand (in official competitions, the ball has a diameter of 107-110 $\mathrm{mm}$ ). Mackey (1987) believes that distributing the weight of the ball between both hands does not cause premature fatigue of the throwing arm.

b) the basic stance - is important in the game of bocce because it allows the player to either have good visibility of the pallina and already released balls or throw the pallina and ball/balls correctly and precisely.

In Bocce Coaching Guide (Special Olympics, 2005), two basic positions are mentioned:

1. standing position - used when the athlete wants to perform a throw in which the ball moves slowly onto the court surface and gets as close to the pallina as possible in order to gain points;

2. stepping position - is a continuation of the standing position; the athlete steps forward with the rear foot (on the same side as the throwing arm) when the arm with the ball is swinging back; the position can also be performed with a four-step approach; it is used to displace the opponent's ball/ balls placed near the pallina or to move the pallina away from the opponent's ball/balls.

However, regardless of the basic stance adopted, the throwing arm performs a forward, backward and again forward swing movement. Thus, the ball is imparted an appropriate speed. The other arm has the role of maintaining body balance.

c) the grip - consists in the contact between the throwing hand and the ball (the fingers are spread evenly across the bottom of the ball, except for the thumb, which is placed laterally to hold the ball; the hand can be in supination or pronation, depending on the game situation). Players with small hands may not be able to hold the ball; in this case, the grip will not be performed with the hand in pronation, but with both hands (Special Olympics, 2005).

d) the release - is the element by which the pallina or ball is delivered and rolls down the court. There are many systematisations of the ball release. Bocce Coaching Guide (2005) 
describes two types of ball release: pointing shot and hitting shot. Szocs (1971) mentions several types of ball release, but we believe that straight-line release and diagonal release are most often used in the game of bocce played by people with Down syndrome.

Motor skills specific to the game of bocce can also be learned by people with Down syndrome, but those involved must be careful and show a lot of patience. Throughout the learning process, it should not be ignored that learning is closely related to memory ability (Lakatos \& Moldovan, 2000), which is low in subjects with Down syndrome. Studies conducted by Leonard et al. (2002) have found that older people with Down syndrome have better memory. However, regardless of age, they must persevere even if they do not have this tendency (particularly children) (Rondal \& Perera, 2006).

\section{Purpose of study}

The purpose of this study is to identify how athletes with Down syndrome have learned and enhanced the technique specific to the game of bocce, especially the ball release technique.

\section{Hypothesis}

The systematic and constant application of an exercise programme leads to the learning and consolidation of motor skills specific to the game of bocce in people with Down syndrome.

\section{Methodology}

\section{Participants}

The study included 16 athletes with Down syndrome, 10 children and 6 adults ( 8 girls and 8 boys). They represented a part of the target group within the Erasmus+ Sport 590526 project, which aimed at helping children and young people with mental retardation to learn and consolidate the technique specific to the game of bocce.

Within the project, athletes participated in bocce training sessions for 17 months (1 lesson per week). Each lesson lasted 60 minutes. The means used were in compliance with the recommendations made by specialists regarding the exercise intensity. Thus, the exercises used were dosed so that the intensity was moderate (Matute-Llorente et al., 2013) to high (FragalaPinkham et al., 2010).

We mention that this bocce training was additional to the specialised intervention programme designed by the organisation to which the research subjects belonged. Therefore, bocce training was added to motor interventions they had to complete during a week, knowing that motor activity was part of the daily schedule for subjects with Down syndrome (FragalaPinkham et al., 2010; Malak et al., 2013; Matute-Llorente et al., 2013; Asonitou et al., 2018; Makhov et al., 2019). Thus, through the effort made in bocce training, athletes needed to burn the $2000 \mathrm{kcal}$ (Kerstiens \& Greem, 2015) they had to consume per week. To this purpose, they performed aerobic exercise for at least 3-7 days, of which 3-4 days contained exercises whose intensity was $40 \%$ to $80 \%$ of maximum oxygen consumption $\left(\mathrm{VO}_{2}\right)$ (Kerstiens \& Greem, 2015). 
To note that we had the parents' agreement to both involve the children with Down syndrome in the research and interpret and publish the research data. During the research, we respected the provisions of the Declaration of Helsinki (World Medical Association, 2013) as regards the ethical principles applied to studies performed on human subjects.

\section{Research methods}

- documentation method - helped us to create the theoretical background of the paper. We studied the national and international literature about motor learning in people with mental retardation. We also used online resources to find international studies focused on a similar topic regarding the same social category;

- experiment method - this study was based on an ameliorative longitudinal experiment that tracked the level of motor skill learning specific to the game of bocce by athletes with mental retardation - Down syndrome. To assess this level, we used the official divisioning test proposed by Special Olympics International (2018) and applied to establish value series in competitions for people with intellectual disabilities. Through this complete and complex test, we assessed the level of consolidation of motor skills specific to the game of bocce, but also related to estimating the ball throw distance, precision and direction.

The test consisted of three series of 8 ball throws ( 24 throws in total). The ball had to stop as close as possible to a mark where the pallina was placed. The pallina mark was placed at three different distances measured from the back-board line $-9.15 \mathrm{~m}, 12.20 \mathrm{~m}$ and $15.24 \mathrm{~m}$. For each distance, the athlete had to throw the balls from the shooting line. The balls were thrown alternately from one side and the other side of the court (the 9.15-m and 15.24-m throw from one side of the court, and the 12.20-m throw from the other side of the court).

After throwing all the 8 balls to the first mark, the distance between the mark/pallina and the nearest 3 balls was measured. The measured values were added to indicate the athlete's performance for that distance. The same method was used for the other two distances -16 throws. At the end of the test, all three performances were added together to find the final score for the previously mentioned test.

In this study, the test was applied three times: initial testing (March 2018), which was performed at the beginning of the training lessons, when athletes did not know the game of bocce. In this case, they were shown what they had to do, and they did. Intermediate testing was applied after 8 months of training (January 2019), and final testing took place after 17 months of training (November 2019). We mention that the months of training were not consecutive because there were also holiday periods that overlapped school holidays during which the association where the athletes were authorised did not have activity either.

Throughout the 17 months, athletes had 55 bocce training sessions. It should be noted that participation in these lessons was not $100 \%$ for any athlete. Due to several variables such as seasonal illness, parent impossibility to bring them to bocce training, other school activities, etc., the average number of workouts in which the research subjects participated was 37 .

- mathematical method - consisted in calculating the sum of the results obtained by athletes in the three tests;

- graphical method - the results obtained from assessments were graphically expressed, which facilitated the presentation of data. 


\section{Results}

Data analysis and interpretation has revealed the following results (Figures 1-4).

Figure 1 shows that the results obtained by two girl athletes are lower from one test to another. If, for athlete no. 2 , an improvement in the throwing technique is obvious from one test to another, for athlete no. 1, the consolidation of the technique is highlighted in the final test, the results having close values between the other two tests.

For the other two girl athletes, the test results are fluctuating. Athlete no. 3 had poorer results in the final test compared to the initial test. Athlete no. 4 had a better result in the intermediate test than in the initial test, and the result in the final test was better than the result obtained in the intermediate test.

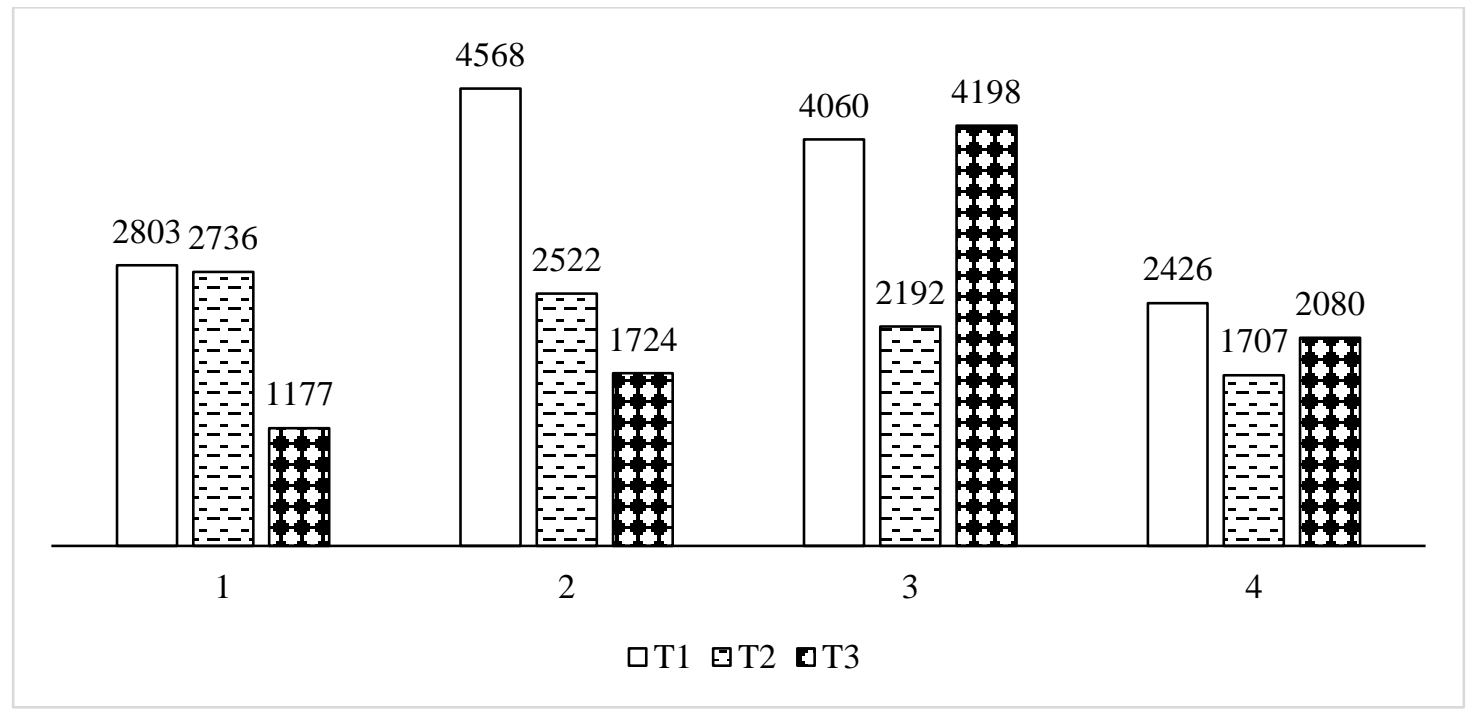

Figure 1. Results obtained by girl athletes under 18 years of age

In this category of athletes, too, results that differ from one test to another are noted. Only three athletes improved their performance. The obvious improvement of the technique is observed in athlete no. 6. Surprisingly, athlete no. 1 obtained increasingly better results from one test to another. Athletes no. 2 and no. 4 have visible fluctuations from one test to another. 


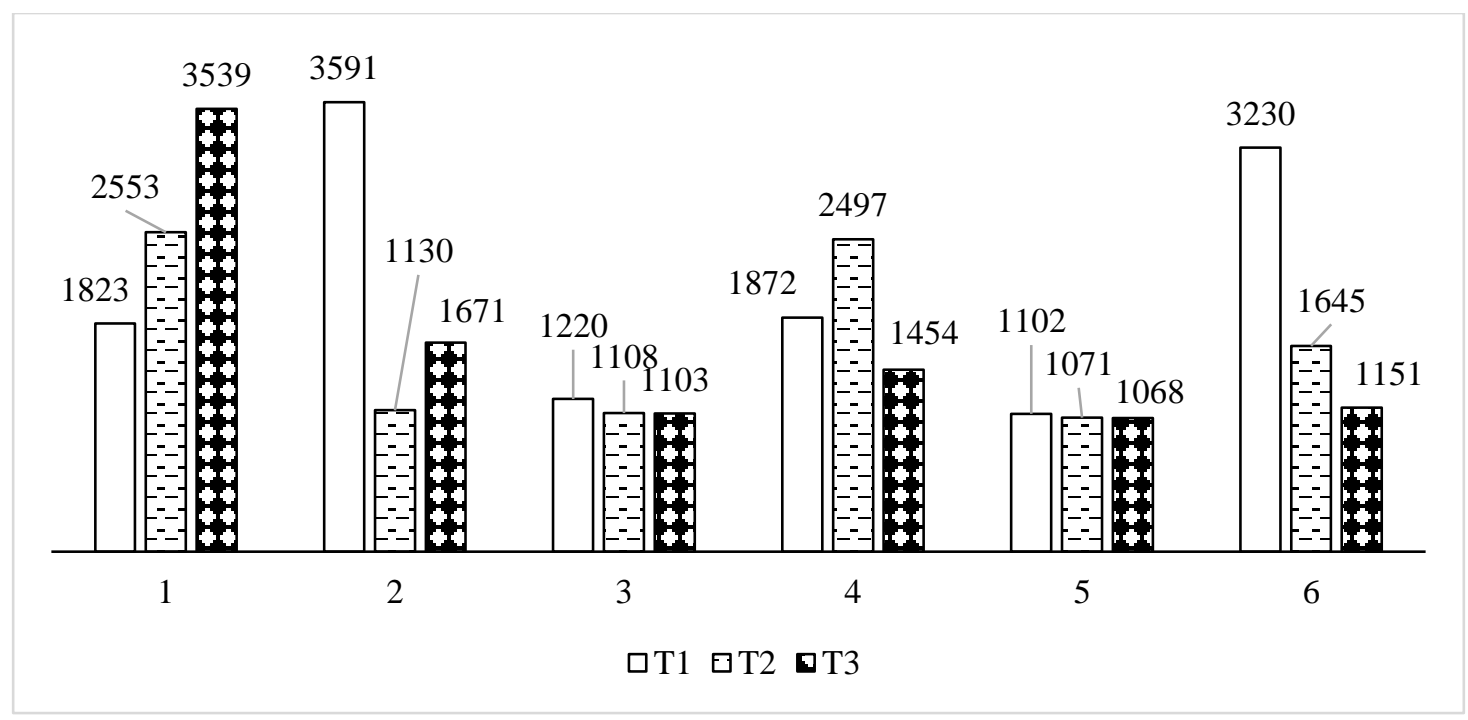

Figure 2. Results obtained by male athletes under 18 years of age

Unlike the results presented above, girl athletes over 18 years of age recorded improvements from one test to another. Only athlete no. 4 has a poorer result in the final test compared to the intermediate test, but the difference is very small.

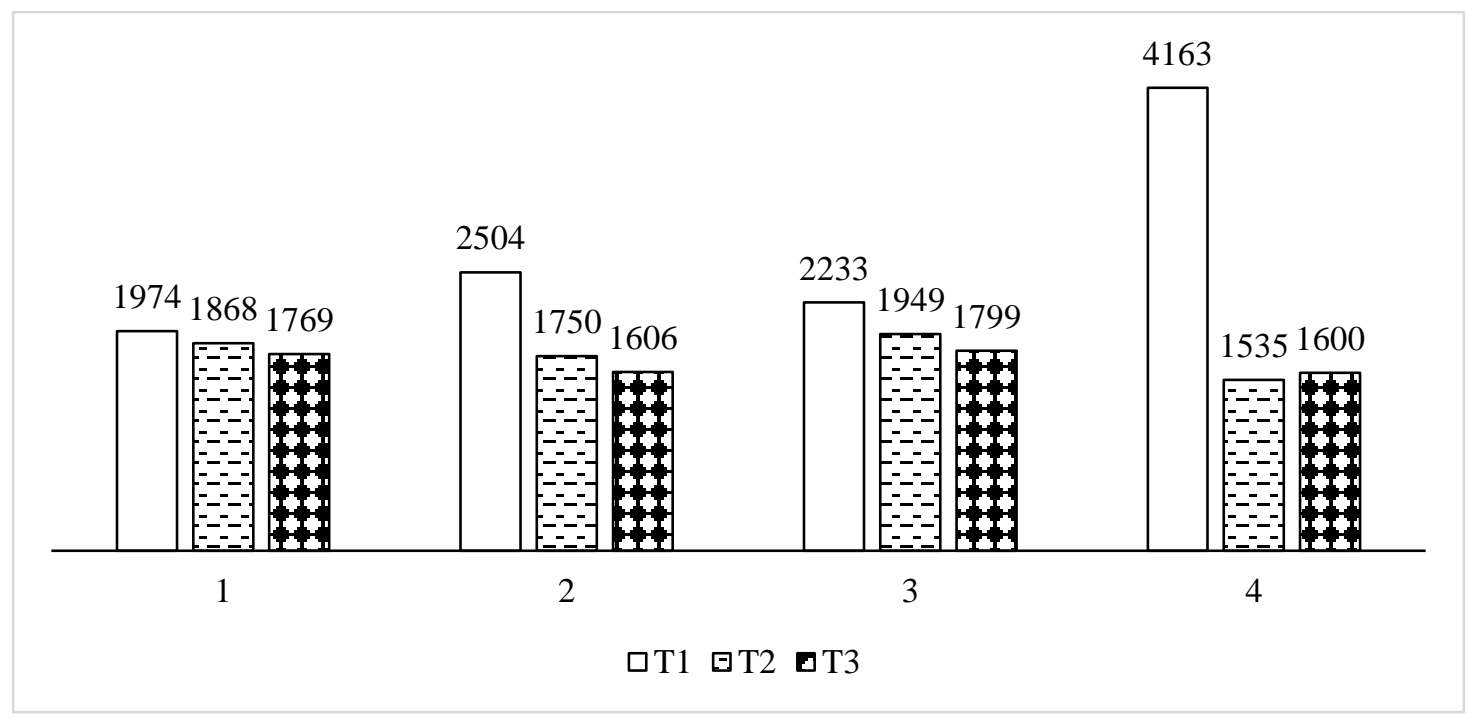

Figure 3. Results obtained by girl athletes over 18 years of age

Adult athletes also show a downward trend in the results even if athlete no. 1 has recorded a small difference between the second and third tests. 


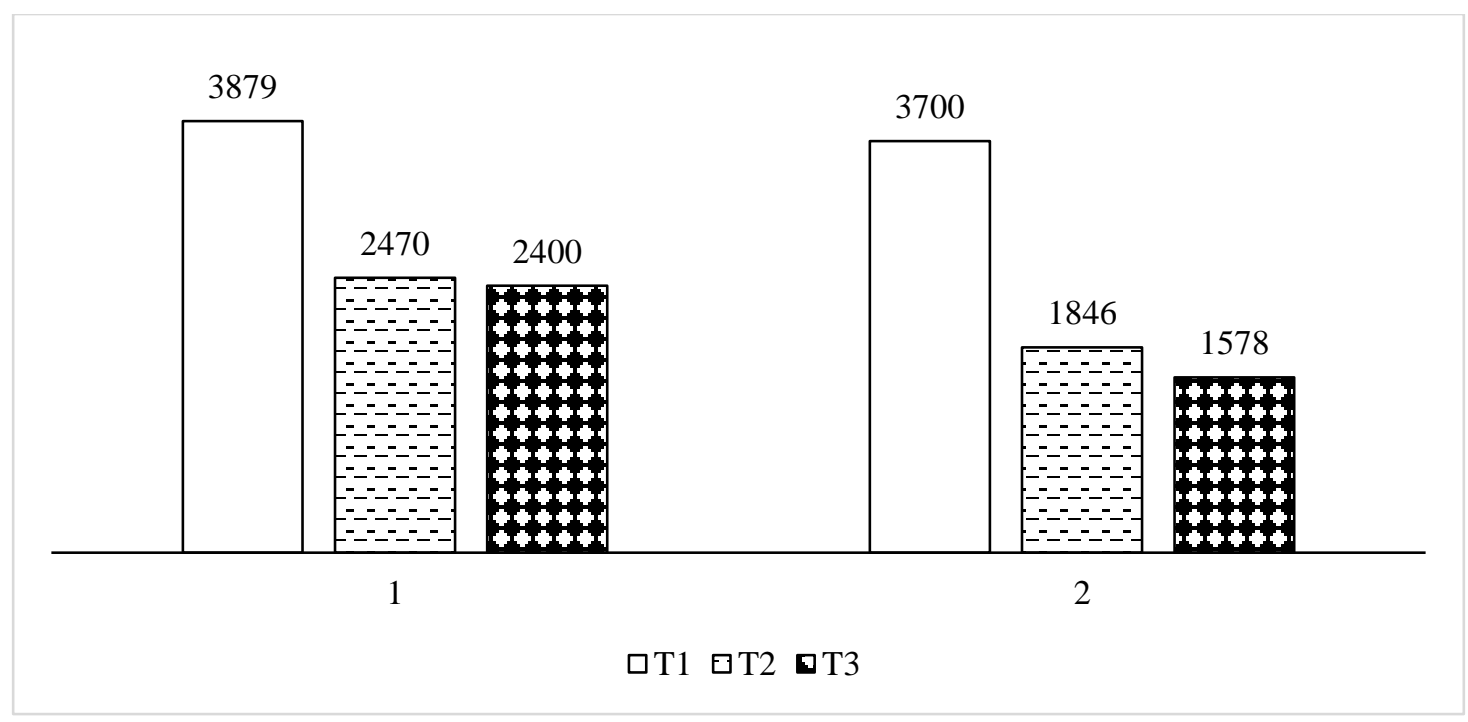

Figure 4. Results obtained by male athletes over 18 years of age

The age-related performance achieved by our athletes at the time of testing confirms the data from other studies previously mentioned in this paper.

In the case of athletes under the age of 18 , we could notice that 5 of them had oscillating performance from one test to another. The other 5 athletes improved their performance, but this improvement did not have the same evolution.

Athletes over the age of 18 improved their performance from one test to another, the sum of their results being increasingly smaller. This proves that they have consolidated their playing technique, especially the ball throwing technique.

The results obtained by our athletes support the idea that motor performance can be improved if an organised and systematic action is taken to educate motor behaviour that influences the performance of the whole body.

\section{Discussion}

Bocce can be played by people with Down syndrome, including those diagnosed with atlantoaxial instability, because the movements performed during the game do not require excessive flexion of the neck (Morton et al., 1995).

The skills involved by this game are easy and can be practiced in the subject's independent activity with family or friends. Movements can become a support of motor activity for people with Down syndrome, a means but also a method of maintaining health (Davlet'yarova et al., 2015).

The results recorded by 6 of the athletes whose performance fluctuates from one test to another also confirm the opinions of specialists regarding the way in which people with Down syndrome learn. Mureșan and Coman (2011) believe that these subjects have periods during which motor acquisitions occur very quickly, at a pace close to that of non-disabled individuals. However, these periods alternate with periods of stagnation or obvious regression. This aspect is also captured in our study, the performance of some subjects in improving their technique 
having periods of decrease. This is best highlighted by athlete no. 1 aged under 18, for whom all results are increasingly poorer.

Obviously, the tests are also influenced by the physical and mental state of the athlete during the test, by the fatigue accumulated both on the testing day and in the period preceding the test. We should mention that 10 of the research subjects were still students at special schools, therefore they came to the bocce training directly from school (after 7-8 classes). Of the 10 athletes, 5 had variable results, their improvements being inconclusive.

Even if the improvement of the technique is not clear, stimulation is recommended to continue, knowing that greater or lesser gains can occur on all levels (Malak et al., 2013; Terblanche \& Boer, 2013; Bota, 2016) until old age, but practice is the prerequisite for maintaining these acquisitions.

Another issue that must be taken into account is the age of the athletes. It has been demonstrated that girls with Down syndrome are more sedentary than boys (Bota, 2016), and adults have better memory (Leonard et al., 2002), which can also leave its mark on motor learning.

It is important for motor skills to be correctly learned in technical terms, regardless of the age at which learning takes place.

\section{Conclusion}

Learning and consolidating the technique is important for athletes with Down syndrome because they influence the efficiency of performing motor skills, specifically the throwing skills in the game of bocce. Progress is little and in most cases is visible after a long time. At the same time, the amount of acquired motor skills may vary from a period of time to another. For this reason, a lot of patience is required throughout learning.

The game of bocce can be an option for spending one's free time in a pleasant way.

\section{Authors' Contributions}

All authors have equally contributed to this study and should be considered as main authors.

\section{Acknowledgments}

We thank the athletes, parents and volunteers who participated in this research.

\section{Acknowledgment}

The paper is an integral part of the Erasmus+ Sport Project - Sport together, active forever (590526-EPP-1-2017-1-RO-SPO-SSCP), a project co-financed by the European Union. The content of the paper reflects only the authors' views, and the Agency and Commission are not responsible for any use that may be made of the information contained. 


\section{References}

Asonitou, K., Mpampoulis, T., Irakleous-Paleologou, H., \& Koutsouki, D. (2018). Effects of an adapted physical activity program on physical fitness of adults with intellectual disabilities. Advances in Physical Education, 8(3), 321-336. https://doi.org/10.4236/ape.2018.83028

Bălan, V., Mujea, A. M., \& Gherghel, C. (2019). Bocce: Practical guide. București: Discobolul.

Bota, A. (2016). Inițiere motrică timpurie: Exerciții pentru copiii cu dizabilități intelectuale [Early motor initiation: Exercises for children with intellectual disability]. București: Fundația Special Olympics Romania.

Braneț, C. (2016). Repere în antrenamentul atletic al copiilor de 6-9 ani (copii III) [Landmarks in the athletic training of children aged 6-9 (children III)]. București: Discobolul.

Davlet'yarova, K. V., Korshunov, S. D., \& Kapilevich, L. V. (2015). Biomechanical bases of rehabilitation of children with cerebral palsy. New Operational Technologies, 1688(1). https://doi.org/10.1063/1.4936010

Doban, M. (2008). Rolul terapiei prin mișcare în procesul de reabilitare psihosocială a persoanelor cu handicap [Role of movement therapy in the process of psychosocial rehabilitation of disabled people]. Buletin Științifico-Metodic, 2, 11-21. București: ANEFS.

Dragnea, A., Bota, A., Stănescu, M., Teodorescu, S., Șerbănoiu, S., \& Tudor, V. (2006). Educație fizică și sport - Teorie și didactică [Physical education and sport - Theory and didactics]. București: FEST.

Fidler, D. J. (2005). The emerging Down syndrome behavioral phenotype in early childhood. Infants \& Young Children, 18(2), 86-103.

https://psycnet.apa.org/doi/10.1097/00001163-200504000-00003

Fragala-Pinkham, M., O’Neil, M. E., \& Haley, S. M. (2010). Summative evaluation of a pilot aquatic exercise program for children with disabilities. Disability and Health Journal, 3(3), 162-170. https://doi.org/10.1016/j.dhjo.2009.11.002

Gilderthorp, R., Burns, J., \& Jones, F. W. (2017). Classification and intellectual disabilities: An investigation of the factors that predict the performance of athletes with intellectual disability. Journal of Clinical Sport Psychology, 12(3), 285-301. https://doi.org/10.1123/jcsp.2017-0018

Kazakova, T. E. (2018). Problems of the development of bocce in Russia. Research Journal of Pharmaceutical, Biological and Chemical Sciences, 9(4), 386-392. https://www.rjpbcs.com/pdf/2018_9(4)/[47].pdf

Kerstiens, R. L., \& Green, M. (2015). Exercise in individuals with Down syndrome: A brief review. International Journal of Exercise Science, 8(2), 192-201. https://core.ac.uk/reader/43647230

Lakatos, G., \& Moldovan, M. (2000). O dovadă că se poate! [Proof that it is possible!]. Oradea: Asociaţia Down Oradea.

Lauteslager, P. E. M. (2005). Copiii cu sindromul Down: Dezvoltare motorie și intervenție [Children with Down syndrome: Motor development and intervention]. Craiova: Sud.

Leonard, S., Msall, M., Bower, C., Tremont, M., \& Leonard, H. (2002). Functional status of school-aged children with Down syndrome. Journal of Paediatrics and Child Health, 38(2), 160-165. https://doi.org/10.1046/j.1440-1754.2002.00736.x

Mackey, R. T. (1987). Bowling (4th ed.). Palo Alto: Mayfield.

Makhov, A. S., \& Medvedev, I. N. (2019). Functional characteristics of children with Down syndrome and possibilities of their correction with the help of athletic activity in Russia. Bali Medical Journal, 8(2), 587-591. https://dx.doi.org/10.15562/bmj.v8i2.1097 
Malak, R., Kotwicka, M., Krawczyk-Wasielewska, A., Mojs, E., \& Samborski, W. (2013). Motor skills, cognitive development and balance functions of children with Down syndrome. Annals of Agricultural and Environmental Medicine, 20(4), 803-806. https://pdfs.semanticscholar.org/39ac/ae2630fb9d467e181710032fcd95f69037df.pdf

Malak, R., Kostiukow, A., Krawczyk-Wasielewska, A., Mojs, E., \& Samborski, W. (2015). Delays in motor development in children with Down syndrome. Medical Science Monitor, 21, 1904-1910. https://dx.doi.org/10.12659\%2FMSM.893377

Marcu, V., Blândul, V. C., Beleneşi, M., Marinescu, M., Druţă, F., \& Dan, M. (2007). Vademecum de psihopedagogie specială [Vade Mecum of special psycho-pedagogy]. Oradea: Editura Universității din Oradea.

Marques-Aleixo, I., Querido, A., Figueiredo, P., Vilas-Boas, J. P., Corredeira, R., Daly, D., \& Fernandes, R. J. (2013). Intracyclic velocity variation and arm coordination assessment in swimmers with Down syndrome. Adapted Physical Activity Quarterly, 30(1), 70-84. https://doi.org/10.1123/apaq.30.1.70

Matute-Llorente, A., González-Agüero, A., Gómez-Cabello, G., Rodríguez V., \& Casajús J. A. (2013). Physical activity and cardiorespiratory fitness in adolescents with Down syndrome. Nutricion Hospitalaria, Pediatría, 28(4), 1151-1155. https://doi.org/10.3305/nh.2013.28.4.6509

Morton, R. E., Khan, M. A., Murray-Leslie, C., \& Elliott, S. (1995). Atlantoaxial instability in Down's syndrome: A five year follow up study. Archives of Disease in Childhood, 72(2), 115-119. https://doi.org/10.1136/adc.72.2.115

Mureșan, D. M. \& Coman, M. F. (2011). O șansă dată copilului cu sindrom Down [A chance given to the child with Down syndrome]. Cluj Napoca: Emma Books.

Neagu, N., \& Papp, E. (2012). Improving social and professional integration of people with Down syndrome by means and kinetic techniques. Procedia - Social and Behavioral Sciences, 33, 493-497. https://doi.org/10.1016/j.sbspro.2012.01.170

Rondal, J. A., \& Perera, J. (2006). Down syndrome: Neuro-behavioural specificity. Chichester: John Wiley 7 Sons, Ltd.

Sharav, T., \& Bowman, Y. (1992). Dietary practices, physical activity, and body-mass index in a selected population of Down syndrome children and their siblings. Clinical Pediatrics, 31(6), 341-344. https://doi.org/10.1177/000992289203100605

Special Olympics. (2005). Bocce coaching guide: Planning a bocce training \& competition season.https://sosd.org/images/files/Coaching_Guides/Bocce_Coaching_Guide.pdf

Special Olympics International. (2018). Bocce: Sport rules. https://media.specialolympics.org/resources/sports-essentials/sport-rules/SportsEssentials-Bocce-Rules-2018.pdf

Szocs, L. (1971). Popice: Metodica învățării și perfecționării [Bowling: The methodology of learning and improvement]. București: Stadion.

Terblanche, E., \& Boer, P. H. (2013). The functional fitness capacity of adults with Down syndrome in South Africa. Journal of Intellectual Disability Research, 57(9), 826-836. https://doi.org/10.1111/j.1365-2788.2012.01594.x

Teodorescu, S., Bota, A., \& Stănescu, M. (2007). Educaţie fizică și sport adaptat pentru persoanele $\mathrm{cu}$ deficiențe senzoriale, mintale și defavorizate social [Adapted physical education and sport for sensory and mental impairments and socially disadvantaged people]. București: Semne.

World Medical Association. (2013). Declaration of Helsinki: Ethical principles for medical research involving human subjects. JAMA, 310(20), 2191-2194. https://www.wma.net/wp-content/uploads/2016/11/DoH-Oct2013-JAMA.pdf 